\title{
Fluorescence quenching of versatile fluorescent probes based on strongly electron-donating distyrylbenzenes responsive to aromatic chlorinated and nitro compounds, boronic acid and $\mathrm{Ca}^{2+}$
}

\author{
Jiro Motoyoshiya,* Zhu Fengqiang, Yoshinori Nishii, Hiromu Aoyama \\ Department of Chemistry, Faculty of Textile Science and Technology, Shinshu University, \\ Ueda, Nagano 386-8567, Japan.
}

Fax: 026821 5391; Tel: +81 268 5402; E-mail address: jmotoyo@giptc.shinshu-u.ac.jp

\begin{abstract}
The fluorescence quenching behavior of two distyrylbenzenes (DSBs) newly prepared bearing strongly electron-donating groups was investigated. Several chlorinated and nitro compounds quench the fluorescence of both DSBs with various efficiencies depending on the electron-withdrawing properties; the strongly electron-withdrawing compound, such as 2,4,5-trichlorophenol and 2,4-dinitrofluorobenzene, effectively diminish the fluorescence intensities of the DSBs. Since the fluorescence quenching constants and the reduction potentials of the quenchers are linearly related, these quenching phenomena are attributed to the photo-induced electron transfer (PET) process. The fluorescence quenching was also detected in the interaction between the azacrown DSB and phenylboronic acid, while the fluorescence recovers by adding triethylamine. On the other hand, the azacrown DSB selectively interacts with $\mathrm{Ca}^{2+}$ to decrease its fluorescence intensity, but the DSB with the dimethylamino groups did not. These results suggest a potential use of these types of compounds as sensors for strongly electron-withdrawing substances and a suitable metal cation.
\end{abstract}

Keywords: Distyrylbenzene, Fluorescence quenching, Azacrown ether, Photo-induced electron transfer, Metal cation recognition, Reduction potential 


\section{Introduction}

Considerable attention has been paid to the fluorescent sensors responsive to a wide range of substances including metal ions, and organic and inorganic compounds [1-7], some of which are based on the inhibition of a photo-induced electron transfer (PET) process caused by the interaction of the electron-donor sites and the target substances [8-10]. Various fused aromatic compounds with a strong fluorescence such as pyrene, anthracene, etc. have been frequently used for the fluorescent sites [11.12]. In general, distyrylbenzenes are strongly fluorescent and very versatile compounds because of availability of a number of derivatives with various properties such as absorption, fluorescence, oxidation potential, and solubility toward various media, which can be controlled by the electronic nature of the substituens on the distyrylbenzenes [13-16].

Detection of chlorinated or nitro compounds in the environments is a very important problem because they affect human lives as the relics of agricultural chemicals or explosives [17-20]. Therefore, the development of a method for their accurate and rapid detection is required. Some chemosensory devices for this purpose utilize the fluorescence quenching phenomena attributed to the electronic interaction between the strongly fluorescent compounds and the target molecules that are strongly electron-withdrawing. On the other hand, some boron compounds, such as boric acids and their esters, are also known to act as fluorescence quenchers and interact with the ligands such as anions, amines and alcohols, changing the orbital from $\mathrm{sp}^{2}$ to $\mathrm{sp}^{3}$ [21.22], which led to the development of many boron complexes bearing a fluorophore or chromophore as sensing agents for inorganic anions and sugars [23-26]. The fluorescent response of these sensing agents is based on the change in the efficiency of the PET process between the fluorophores and boron moieties or the energy transfer from the donor to the acceptor.

In this paper, we report the spectral properties of two strongly electron-donating and fluorescent distyrylbenzenes ( $\mathbf{1}$ and $\mathbf{2}$ ) bearing two alkoxy groups on the central benzene rings and amino groups on each terminal benzene ring. (Fig. 1). Based on such properties, they will interact with electron-accepting substances such as chloro, nitro and boronic compounds. Since the azacrown moiety is known to act as a recognition site for a suitable metal cation [27-30], the interaction of the distyrylbenzenes with the azacrown moieties will form a chemosensor for a suitable metal cation. We show that these types of distyrylbenzenes have the possible potential of being used as chemosensors for suitable substances.

\section{Fig. 1}




\section{Experimental}

\subsection{Reagents and apparatus}

Solvents were purified and dried by the standard method. Two distyrylbenzenes were synthesized as described bellow. Phenylboronic acid was prepared according to the known method [31]. Other chemicals were used as purchased. ${ }^{1} \mathrm{H}$ and ${ }^{13} \mathrm{C}$ NMR spectra were recorded on a Bruker AVANCE-400 at $400 \mathrm{MHz}$ and $100 \mathrm{MHz}$ respectively. The chemical shifts $(\delta)$ are reported in ppm downfield from TMS as internal standard or from the residual solvent peak. Coupling constants $(J)$ are reported in Hz. Analytical TLC was carried out on precoated silica gel 60F-254 plates (E. Merck). Column chromatography was performed on silica gel (E. Merck). Absorption and fluorescence spectra were recorded on a U-3310 spectrometer (Hitachi) and on a RF-5000 spectrometer (Shimadzu), respectively. Fluorescence quantum yields were estimated using 9,10-diphenylanthracene ( $\Phi_{\mathrm{F}}=0.91$ in benzene) as a standard. Cyclic voltammetry was performed at room temperature with a three-compartment cell in dry acetonitrile solution containing the substrate (ca. $\left.10^{-4} \mathrm{M}\right)$ and a supporting electrolyte $(0.1 \mathrm{M}$ tetrabutylammonium perchlorate). Pt disk, Pt wire, and saturated calomel electrode (SCE) were used as the working, counter, and reference electrodes, respectively. The scan rate was $100 \mathrm{mV} \mathrm{s}^{-1}$.

\subsection{Synthesis of (E,E)-2,5-Bis(2'-ethylhexyloxy)-1,4-bis(4"-N-dimethylstyryl)benzene (1)}

To a suspension of tert-BuOK $(1.41 \mathrm{~g}, 12.60 \mathrm{mmol})$ in DMF $(10 \mathrm{~mL})$ was added a solution (20 $\mathrm{mL}$ ) of 2,5-bis(2'-ethylhexyloxy)-1,4-bis(diethylphosphonomethyl)benzene (2.00 g, $3.15 \mathrm{mmol})$ in DMF $(20 \mathrm{~mL})$ and stirred for $30 \mathrm{~min}$. at room temperature. To the slurry was added dropwise a solution of 4- $N$-dimethylaminobenzaldehyde $(0.78 \mathrm{~g}, 5.23 \mathrm{mmol})$ in DMF $(10 \mathrm{~mL})$. After being stirred for $8 \mathrm{~h}$ at room temperature, the solvent was removed by distillation under a reduced pressure and then a saturated ammonium chloride solution was added to the residue. The product was extracted with ether and the organic phase was dried over anhydrous $\mathrm{Na}_{2} \mathrm{SO}_{4}$. After removal of the solvent, the product was purified by column chromatography on silica gel with benzene as an eluant to give 1 ( $0.62 \mathrm{~g}, 38 \%$ ) as an oil. ${ }^{1} \mathrm{H}$ NMR (400 MHz, $\left.\left.\mathrm{CDCl}_{3}\right) \delta 0.90 \mathrm{t}, 6 \mathrm{H}, J=7.2 \mathrm{~Hz}\right), 0.99$ $(\mathrm{t}, 6 \mathrm{H}, J=7.2 \mathrm{~Hz}), 1.34-1.60(\mathrm{~m}, 16 \mathrm{H}), 1.75-1.83(\mathrm{~m}, 2 \mathrm{H}), 2.98(\mathrm{~s}, 12 \mathrm{H}), 3.93(\mathrm{~d}, 4 \mathrm{H}, J=5.2 \mathrm{~Hz})$, $6.72(\mathrm{~d}, 4 \mathrm{H}, J=8.4 \mathrm{~Hz}), 7.05(\mathrm{~d}, 2 \mathrm{H}, J=16 \mathrm{~Hz}), 7.09$ (s, 4H), 7.29 (d, 2H, J=16 Hz), 7.41 (d, 2H, $J=8.40 \mathrm{~Hz}) .{ }^{13} \mathrm{C} \mathrm{NMR}\left(100 \mathrm{MHz}, \mathrm{CDCl}_{3}\right) \oint 11.82,14.60,23.43,24.15,30.33,30.75,38.05,43.62$, $77.12,112.45,113.08,120.43,124.42,124.83,126.21,127.12,143.76,148.07$. 
(E,E)-2,5-bis(2'-ethylhexyloxy)-1,4-bis [4“-(N-monoaza-15-crown-5)-styryl]benzene (2)

This compound was prepared similarly to the procedure described above using tert-BuOK (0.71 g, $6.33 \mathrm{mmol}), 2,5$-bis(2'-ethylhexyloxy)-1,4-bis(diethylphosphonomethyl)benzene (1.00 g, $1.57 \mathrm{mmol})$ and 4-( $N$-monoaza-15-crown-5)benzaldehyde $(0.75 \mathrm{~g}, 2.32 \mathrm{mmol})$ in $45 \%(0.51 \mathrm{~g})$ yield. ${ }^{1} \mathrm{H}$ NMR $\left.\left(400 \mathrm{MHz}, \mathrm{CDCl}_{3}\right) \delta 0.88 \mathrm{t}, 6 \mathrm{H}, J=7.3 \mathrm{~Hz}\right), 0.94$ (t, $\left.6 \mathrm{H}, J=7.3 \mathrm{~Hz}\right), 1.34-1.38$ (m, $16 \mathrm{H}), 1.75-1.83(\mathrm{~m}, 2 \mathrm{H}), 3.62-3.69(\mathrm{~m}, 32 \mathrm{H}), 3.78(\mathrm{t}, 8 \mathrm{H}, J=6.0 \mathrm{~Hz}), 3.93(\mathrm{~d}, 4 \mathrm{H}, J=5.2 \mathrm{~Hz})$, $6.45(\mathrm{~d}, 4 \mathrm{H}, J=9.2 \mathrm{~Hz}), 7.02(\mathrm{~d}, 2 \mathrm{H}, J=16 \mathrm{~Hz}), 7.26(\mathrm{~s}, 4 \mathrm{H}), 7.27$ (d, 2H, $J=16 \mathrm{~Hz}), 7.38$ (d, 2H, $J=8.40 \mathrm{~Hz}) .{ }^{13} \mathrm{C}$ NMR $\left(100 \mathrm{MHz}, \mathrm{CDCl}_{3}\right) \oint 11.75,14.54,23.52,24.66,29.69,31.33,40.25,52.98$, $69.02,70.59,70.61,71.73,72.17,110.24,112.07,119.51,126.64,127.17,128.07,128.53,147.42$, 151.29. 


\section{Result and Discussion}

\subsection{Synthesis and spectra of distyrylbenzenes 1 and $\mathbf{2}$}

The distyrylbenzenes $\mathbf{1}$ and $\mathbf{2}$ were prepared by a modification of the Wittig olefination reaction using a 1,4-bis(diethylphosophonomethyl)benzene and the corresponding aromatic aldehydes in the presence of tert-BuOK. Their geometric structures were identified as all $E$-forms, and as shown in Fig. 2a, they exhibit absorptions at 418 and $422 \mathrm{~nm}$ with the large molecular extinction coefficients as $\log \varepsilon: 4.56$ and 4.63 and intense fluorescence with the maximum emission wavelengths located at 482 and $485 \mathrm{~nm}$ with the fluorescence quantum yields of 0.48 and 0.51 for 1 and 2 in THF, respectively. When comparing their spectra of the parent 4,4'-distyrylbenzene without any substituent that has an absorption at $357 \mathrm{~nm}$ and fluorescence at $414 \mathrm{~nm}$ (in dioxane) [32], those of $\mathbf{1}$ and $\mathbf{2}$ significantly shift to the long wavelength regions, which is attributed to the presence of the terminal amino groups because 4,4'-bis(4"-dimethylaminostyryl)benzene, lacking two alkoxy groups, absorbs at $398 \mathrm{~nm}$ and emits at $463 \mathrm{~nm}$ [32,33], in almost the same regions as 1 and 2. A spectral change depending on the property of the solvents was also observed. For instance, almost the same spectra for $\mathbf{2}$ were obtained in THF and in benzene, while the alcoholic solvents affect the spectra to give structureless ones with a decreasing intensity (Fig. 2b). Interestingly, the spectra of 2 measured in aqueous THF change in its structure with a decreasing intensity as the ratio of the water increases (Fig. 2c), which indicates that the hydrogen-bond formation at the amino group sites leads to the change in the ratio of the emission for each transition. Such spectral behavior was also observed for $\mathbf{1}$. Thus, these distyrylbenzenes are sensitive to the environments around them and therefore expected to respond to the change in the chemical situation.

\section{Fig. 2}

\subsection{Fluorescence quenching by chlorinated aromatic compounds}

When distyrylbenzenes $\mathbf{1}$ and $\mathbf{2}$ were dissolved in a mixture of chlorobenzene and THF, their fluorescence intensity decreased depending on the amount of chlorobenzene (Figs. 3a and 3b). The fluorescence quenching effect of dichlorobenzene was greater than chlorobenzene, and in this case, the azacrown 2 was quenched much more effectively than $\mathbf{1}$ (Fig. $3 \mathrm{c}$ and $3 \mathrm{~d}$ ). No structural change of the fluorophores in the solution of the mixtures was confirmed by ${ }^{1} \mathrm{H}$ NMR spectrum. The 
measurements with other chlorinated compounds are summarized in Fig. 4. The stronger the electron-withdrawing character of the coexisting chlorinated compounds, the weaker the fluorescence; 2,4,6-trichlorophenol was the strongest quencher of all those used in this study (Fig. 4). On the other hand, carbon tetrachloride and chloroform also reduced the fluorescence as a result of the photochemical conversion of $\mathbf{1}$ and $\mathbf{2}$ into the non-fluorescent adducts. Such the fluorescence quenching by carbon tetrachloride has been documented in the aromatic fluorescent materials such as anthracene, in which the radical species generated from carbon tetrachloride by the photochemical process reacted with anthracene [34].

\section{$\underline{\text { Fig. } 3}$ and Fig. 4}

\subsection{Fluorescence quenching by nitro compounds}

The fluorescence intensity of $\mathbf{2}$ in THF also gradually decreased with the increasing concentration of nitroethane. The concentration dependence of the quenching efficiency was described as a result of the decrease in both the excitation and fluorescence intensities (Fig. 5a). The fluorescence is almost completely quenched when the concentration of nitroethane exceeds 80 $\mathrm{mg} / \mathrm{mL}$ in a $1 \times 10^{-6} \mathrm{M}$ solution of 1 in THF. On the other hand, the absorption of 1 at $418 \mathrm{~nm}$ does not change in the presence of nitroethane (Fig. 5b), indicating that nitroethane also interacts with the excited state of $\mathbf{1}$. Other nitro compounds, such as nitrobenzene, 4-hydroxynitrobenzene, and 2,4-dinitrofluorobenzene, act as quenchers (Fig. 6) and the quenching efficiency increases with the increasing electron-accepting property of the nitro compounds, among which 2,4-dinitrofluorobenzene is the most effective. A similar, but more effective fluorescence quenching was observed for 2 as can be seen in Fig. 6. As the previously effect reported chemosensory for nitro compound that consisted of the fluorescent poly(phenylene vinylene) with the alkoxy groups is known to be highly sensitive, application of the present DSBs as the fluorescent units would be expected to provide a more effective sensory effect.

\section{Fig. 5 and Fig. 6}

\subsection{Fluorescence quenching to the phenylboronic acid}

Analogous to the nitro compounds, phenylboronic acid also interacts with 2, but not with $\mathbf{1}$. Fig. 7 a shows the fluorescence quenching of 2 by phenylboronic acid that depends on the concentration 
of the quencher. However, the fluorescence was not completely quenched even when excess phenylboronic acid was added. When triethylamine was added to the quenched solution of 2 by phenylboronic acid, the fluorescence recovered (Fig 7b). In this case, triethylamine would acts as an electron-donor rather than a base as mentioned below. This fluorescence property, quenching and recovery, might provide a possibility of $\mathbf{2}$ to be used as a sensor for substances that interact with boronic acid derivatives to set off their electron-accepting abilities.

\section{Fig. 7}

\subsection{Recognition of $\mathrm{Ca}^{2+}$ by the fluorescence quenching}

The change in the electron density of the terminal nitrogen atom affects the fluorescence because a significant decrease in the intensity was observed in the acidic medium; for instance, the fluorescence completely disappeared when the nitrogen atoms were protonated by hydrochloric acid. Accordingly, there is the possibility of metal cation recognition using 2; namely, if the electron-donating character of the terminal azacrown moieties modulates the fluorescence intensity of 2 , chelation by a suitable metal cation that fits the 15 -azacrown-5 can serve as a signal of metal cation recognition. Among several metal cations, such as $\mathrm{Li}^{+}, \mathrm{Na}^{+}, \mathrm{K}^{+}, \mathrm{Rb}^{+}, \mathrm{Ca}^{2+}$ and $\mathrm{Pd}^{2+}$, only $\mathrm{Ca}^{2+}$ was found to effectively reduce the fluorescence intensity of $\mathbf{2}$ in acetonitrile. Absence of the spectral change by $\mathrm{Ca}^{2+}$ in $\mathbf{1}$ supports the fact that the azacrown moieties work as the recognition sites. It is known that the 15 -azacrown-5 moiety forms a complex with $\mathrm{Ca}^{2+}[35,36]$. Fig. 8 shows the fluorescence spectra of $\mathbf{2}$ in the presence of calcium perchlorite. The fluorescence intensity decreased with the increasing amount of $\mathrm{Ca}^{2+}$, but did not completely disappear even when excess $\mathrm{Ca}^{2+}$ was added. A decrease in the fluorescence intensity can be detected when more than 15 times the amount of $\mathrm{Ca}^{2+}$ versus 2 was present. A slight red-shift of the remaining fluorescence spectrum indicated that the complex of $\mathbf{2}$ and $\mathrm{Ca}^{2+}$ also has a weaker fluorescence than the free $\mathbf{2}$ in almost the same region and the spectral change of 2 observed in the presence of $\mathrm{Ca}^{2+}$ is the result of the formation of the weakly fluorescent complex of 2 with $\mathrm{Ca}^{2+}$.

\section{Fig. 8}

\subsection{Fluorescence quenching mechanism}

The possible mechanism of the fluorescence quenching observed in the present study is also regarded to involve a PET process. Considering that there is no change in the absorption spectra of both solutions of $\mathbf{1}$ and $\mathbf{2}$ containing the chlorinated or nitro compounds, the quenching 
phenomenon is due to the electronic interaction between the fluorophores in the excited states as the donors and the chlorinated or nitro compounds as the acceptors. To explore this hypothesis, convenient tests were carried out employing $p$-benzoquinone, a strong electron-acceptor and $p$-dimethoxybenzene, a strong electron-donor. As expected, $p$-benzoquinone also effectively quenched the fluorescence of $\mathbf{1}$, while the fluorescence recovered when $p$-dimethoxybenzene was added to the non-fluorescent solution containing 1 and nitroethane, supporting the involvement of a PET process. We also investigated the electrochemical properties in order to distinguish the difference in the electron-donating abilities between $\mathbf{1}$ and $\mathbf{2}$ by cyclic voltammetry (CV) measurements. The fluorescence of the former was not quenched by phenylboronic acid, but that of the latter decreased in the presence of the quencher. The half-wave oxidation potentials $\left(E_{1 / 2}\right)$ of 1 and 2 are $0.41 \mathrm{~V}$ and $0.49 \mathrm{~V}$ (vs SCE), respectively, which suggests that the azacrown moiety is inclined to release an electron more easily than the dimethylamino group and explains the difference in the spectral behavior in the presence of the quenchers.

When the relation between the fluorescence intensity and the concentration of the electron-acceptors is supported by the following equations for the complex with a 1:1 stoichiometry, the association constant, $K$, for the equilibrium can be related to the concentration of the electron-acceptor [A] as expressed by the following equation [35].

$$
\frac{I_{o}}{I-I_{o}}=\frac{I_{o}}{I_{\max }-I_{o}}\left(\frac{1}{K[\mathrm{~A}]}+1\right)
$$

where $I_{0}$ and $I$ are the fluorescence intensity monitored in the absence and presence of the electron-acceptor, respectively, and [A] is the total concentration of the electron-acceptor. $I_{\max }$ is the fluorescence intensity of the fully interaction with the electron-acceptor. The relative value of $K$ can be estimated without knowing $I_{\max }$, because the first term on the right side of the equation must be constant. Using the data of Fig. 4 and Fig 6, a plot of $I_{0} /\left(I-I_{0}\right)$ versus [A $]^{-1}$ gave a good linear relationship as shown in Fig. 9 and Fig. 10. The good fit to the equation reveals that $\mathbf{1}$ or $\mathbf{2}$ forms a 1:1 stoichiometric complex with the electron-acceptors, which indicates that electron-acceptors interact at one group of the excited 1 or $\mathbf{2}$ undergoes fluorescence quenching. The relationship between the reduction potentials of the electron-acceptors, the standard of the electron-withdrawing ability, and the reciprocal values of the slope estimated from Fig 9 and $10, K\left(I_{\max }-I_{0}\right) / I_{0}$, is shown in Fig. 11 and Fig. 12. The linear relationship shows that the fluorescence quenching constants are closely rationalized to the electron-accepting ability of the quenchers and strongly suggests the PET process is concerned to fluorescence quenching observed in the present system [36].

\section{Fig. 9, 10, 11, 12}




\section{Conclusion}

We have successfully evaluated the interesting spectral behavior of two strongly electron-donating distyrylbenzenes, $\mathbf{1}$ and $\mathbf{2}$, whose fluorescence is quenched by electron-withdrawing compounds, such as chlorinated and nitro compounds, as well as phenylboronic acid. Recognition of $\mathrm{Ca}^{2+}$ by the 15 -azacrown-5 moiety was also conducted by the selective complex formation, which results in a reduced the fluorescence intensity. Considering the relationship between the fluorescence quenching constants and the reduction potentials of the quenchers, the present quenching phenomena are due to the PET process.

\section{Acknowledgments}

This work was partially supported by the CLUSTER of the Ministry of Education, Culture, Sports, Science and Technology of Japan and the Grants-in-aid for the $21^{\text {st }}$ Century COE Research. J.M is also grateful for the financial support by the Grant-in-aid (16550122) from the Ministry of Education, Culture, Sports, Science and Technology of Japan. 


\section{References}

[1] X. Qi, E. J. Jun, L. Xu, S.-J. Kim, J. S. J. Hong, Y. J. Yoon, J. Yoon, J. Org. Chem. 71 (2006) 2881-2884.

[2] G. Hennrich, K. Rurack, M. Spieles, Eur. J. Org. Chem. (2006) 51-521.

[3] M. Montalti, L. Prodi, N. Zaccheroni. J. Mater. Chem. 15 (2005) 2810-2814.

[4] S.-P. Liu, C. Sa, X.-L. Hu, L. Kong, Spectrochimica Acta Part A. 64 (2006) 817-822.

[5] J. W. Dadge, V.N. Krishnamurthy, R. C. Aiyer, Sensors and Actuators B: Chemical 113 (2006) 805-808.

[6] Z. Zhang, S. Zhang, X. Zhang, Analytica Chimica Acta 541 (2005) 37-46;.

[7] C.-X. Jiao, C.-G. Niu, L.-X. Chen, G.-L. Shen, R.-Q, Yu, Sensors and Actuators B: Chemical 94 (2003) 176-183.

[8] N. Kameta, K. Hiratani, Chem. Lett. 35 (2006) 536-537.

[9] K. Ghosh, G. Masanta, Chem. Lett. 35 (2006) 414-415.

[10] S. A. de Silva, K. C. Loo, B. Amorelli, S. L. Pathirana, M. Nyakirang'ani, M. Dharmasena, S. Demarais, B. Dorcley, P. Pullay, Y. A. Salih, J. Mater. Chem. 15 (2005) 2791-2795.

[11] S. J. M. Koskela, T. M. Fyles, T. D. James, Chem. Commun. (2005) 945-947.

[12] J. Yoon, A. W. Czarnik, J. Am. Chem. Soc. 114 (1992) 5874-5875.

[13] R. Koike, Y. Katayose, A. Ohta, J. Motoyoshiya, Y. Nishii, H. Aoyama, Tetrahedron 61 (2005) 11020-11026.

[14] B.-C Wang, J.-C. Chang, J.-H. Pan, C. Xue, F.-T. Luo, Journal of Molecular Structure: THEOCHEM. 636 (2003) 81-87.

[15] J. Motoyoshiya, N. Sakai, M. Imai, Y. Yamaguchi, R. Koike, Y. Tagaguchi, H. Aoyama, 67 J Org Chem (2002) 7314-7318. 
[16] S. Nakatsuji, K. Matsuda, Y. Uesugi, K. Nakashima, S. Akiyama, G. Katzer, W. Fabian, J. Chem. Soc. Perkin Trans. 1 (1991) 861-867.

[17] K. Yamauchi, A. Ishihara, H. Fukazawa, Y. Terao, Toxicolgy and Applied pharmacology, 187 (2003) 110-117.

[18] M. Alvarez, A. Calle, J. Tamayo, L. M. Lechuga, A. Abad, A. Montoya, Biosensors and Bioelectronics, 18 (2003) 649-653.

[19] H.-X. Wang, T. Lin, F.-L. Bai, A. Kaynak, NATO Science Series, II: Mathematics, Physics and Chemistry. 169 (2004) 459-468.

[20] J.-S. Yang, T. M. Swager, J. AM. Chem. Soc. 120 (1998) 5321-5322.

[21] S. Jacobson, R. Pizer, J. Am. Chem. Soc. 115 (1993) 11216.

[22] M. T. Reetz, C. M. Niemeyer, K. Harms, Angew. Chem., Int. Ed. 30 (1991) 1472.

[23] H. E. Katz, J. Org. Chem. 54 (1989) 2179.

[24] S. J. M. Koskela, T. M. Fyles, T. D. James, Chem. Commun. (2005) 945.

[25] J. Zhao, T. M. Fyles, T. D. James, Angew. Chem., Int. Ed. 43 (2004) 3461.

[26] Z. Zhong, E. V. Anslyn, J. Am. Chem. Soc. 124 (2002) 9014.

[27] H. Cao, D. I. Diaz, N. Dicesare, J. R. Lakowicz, M. D. Heagy, Org. Lett. 4 (2002) 1503.

[28] G. Hennrich, K. Rurack, M. Spieles, Eur. J. Org. Chem. (2006) 516-521.

[29] S. J. M. Koskela, T. M. Fyles, T. D. James, Chem. Commun. (2005) 945-947.

[30] P. Crochet, J.-P. Malval, R. Lapouyade, Chem. Commun. (2000) 289-290.

[31] Y. -J. Wu, L. -R. Y, J. -L. Zhang, M. Wang, L. Zhao, M. -P. Song, J. -F. Gong, ARKIVOC (Gainesville, FL, United States), 9 (2004) 111-121.

[32] A. Heller. J. Chem. Phys, 40 (1964) 2839-2851.

[33] K. Sakai, T. Tsuzuki, J. Motoyoshiya, m. Inoue, Y. Itoh, M. Ichikawa, T. Fujimoto, I. Yamamoto, T. Koyama, Y. Taniguchi, Chem Lett (2003) 968-969. 
[34] J. B. Birks, Photophysics of Aromatic Molecules, Wiley-Interscience, London, 1970, pp. $439-441$.

[35] W. -S. Xia, R. H. Schmehl, C. -J. Li, Chem. Commun. (2000) 695-696.

[36] W. -S. Xia, R. H. Schmehl, C. -J. Li, J. Am. Chem. Soc. 121 (1999) 5599-5600.

[37] J. B. Birks, Photophysics of Aromatic Molecules, Wiley Monographs In Chemical Physics, John Wiley \& Sons Ltd. (1970) Chap. 9. 


\section{Figure legends}

Fig. 1 Structures of distyrylbenzene 1 and 2

Fig. 2 Absorption and fluorescence spectra. (a) Absorption and fluorescence spectra of 1 (dashed line) and 2 (solid line) in THF $\left(1 \times 10^{-5} \mathrm{M}\right)$. (b) 1-5: the fluorescence spectra of $2\left(1 \times 10^{-6} \mathrm{M}\right)$ in THF, benzene, EtOH, $\mathrm{MeOH}, \mathrm{CF}_{3} \mathrm{CH}_{2} \mathrm{OH}$. (c) 1-4: the fluorescence spectra of $2\left(1 \times 10^{-6} \mathrm{M}\right)$ in THF, THF: $\mathrm{H}_{2} \mathrm{O}=4: 1$, THF: $\mathrm{H}_{2} \mathrm{O}=1: 4$, THF: $\mathrm{H}_{2} \mathrm{O}=1: 9$.

Fig. 3 Fluorescence spectra of $1(a, c)$ and $2(b, d)$ in the presence of chlorobenzene and $o$-dichlorobenzene, $[\mathbf{1}]=[\mathbf{2}]=1 \times 10^{-6} \mathrm{M}$ in THF. (a) and (b) 1-5: the concentrations of chlorobenzene are in the order of $0 \mathrm{M}, 5 \times 10^{-3} \mathrm{M}, 1 \times 10^{-2} \mathrm{M}, 2 \times 10^{-2} \mathrm{M}, 3 \times 10^{-2} \mathrm{M}$. (c) and (d) 1-5: the concentrations of $o$-dichlorobenzene are in the order of $0 \mathrm{M}, 5 \times 10^{-3} \mathrm{M}, 1 \times 10^{-2} \mathrm{M}, 2 \times$ $10^{-2} \mathrm{M}, 3 \times 10^{-2} \mathrm{M}$, respectively.

Fig. 4 Quenching efficiency of 1 and 2 in THF $\left(1 \times 10^{-6} \mathrm{M}\right)$ versus the concentration of chlorobenzene, o-dichlorobenzene and 2,4,6-trichlorophenol.

Fig. 5 Absorption and fluorescence spectra of $\mathbf{1}$ in the presence of nitroethane, $[\mathbf{1}]=1 \times 10^{-5} \mathrm{M}$ in THF. (a) 1'-6': the excitation spectra, 1-6: the fluorescence spectra. (b) the absorption spectra. (a) and (b) the concentrations of nitroethane are in the order of $0 \mathrm{M}, 2 \times 10^{-2} \mathrm{M}, 5 \times 10^{-2} \mathrm{M}, 0.1 \mathrm{M}, 0.2$ M, $1 \mathrm{M}$.

Fig. 6 Quenching efficiency of 1 and 2 in THF $\left(1 \times 10^{-5} \mathrm{M}\right)$ versus the concentration of nitroethane, p-nitrophenol, nitrobenzene, and 2,4-dinitrofluorobenzene.

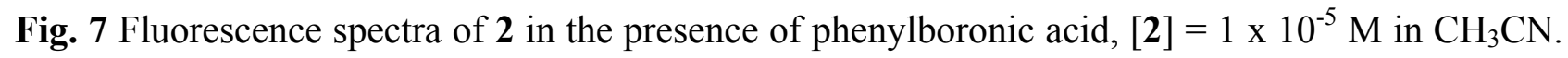
(a) 1-6: the concentrations of phenylboronic acid are in the order of $0 \mathrm{M}, 2 \times 10^{-2} \mathrm{M}, 5 \times 10^{-2} \mathrm{M}, 0.1$ M, 0.2 M, 0.5 M. (b) 1-6: the concentration of phenylboronic acid is $0.5 \mathrm{M}$ and the concentrations 
of triethylamine are in the order of $0 \mathrm{M}, 2 \times 10^{-2} \mathrm{M}, 5 \times 10^{-2} \mathrm{M}, 0.1 \mathrm{M}, 0.2 \mathrm{M}, 0.5 \mathrm{M}$.

Fig. 8 Fluorescence spectra of 2 in the presence of $\mathrm{Ca}^{2+}$, [2] $=1 \times 10^{-6} \mathrm{M}$ in $\mathrm{CH}_{3} \mathrm{CN}$. (a) 1-7: the concentrations of $\mathrm{Ca}\left(\mathrm{ClO}_{4}\right)_{2}$ are in the order of $0 \mathrm{M}, 5 \times 10^{-6} \mathrm{M}, 1 \times 10^{-5} \mathrm{M}, 2 \times 10^{-5} \mathrm{M}, 3 \times 10^{-5} \mathrm{M}$, $4 \times 10^{-5} \mathrm{M}, 5 \times 10^{-5} \mathrm{M}$.

Fig. 9 Theoretical fit of the equation to $I_{0} /\left(I-I_{0}\right)$ versus $[\mathrm{A}]^{-1}$. A is the concentration of the nitro compounds.

Fig. 10 Theoretical fit of the equation to $I_{0} /\left(I-I_{0}\right)$ versus $[\mathrm{A}]^{-1}$. A is the concentration of the chlorinated compounds.

Fig. 11 The relationship between $K\left(I_{\max }-I_{0}\right) / I_{0}$ and reduction potentials (E) of the nitro compounds. Fig. 12 The relationship between $K\left(I_{\max }-I_{0}\right) / I_{0}$ and reduction potentials $(\mathrm{E})$ of the chlorinated compounds. 

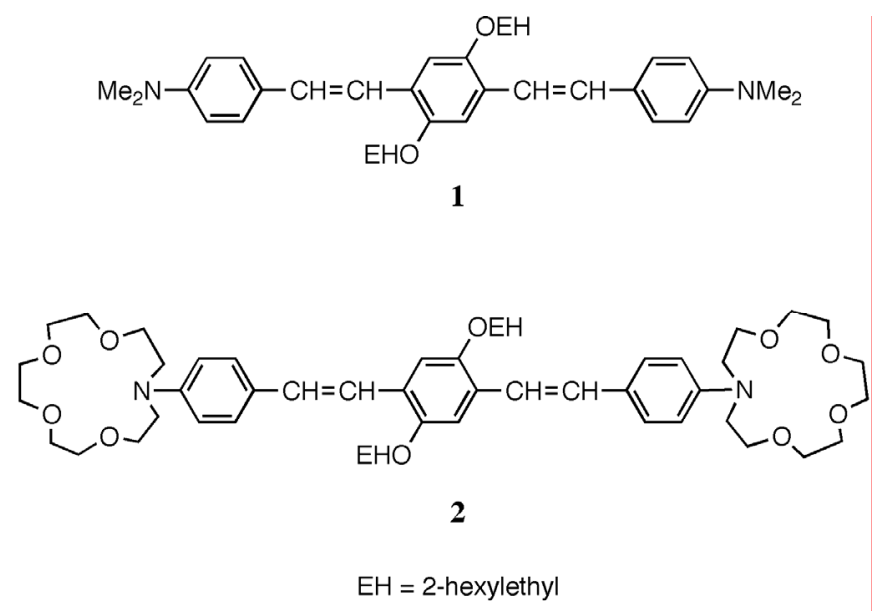

Fig. 1
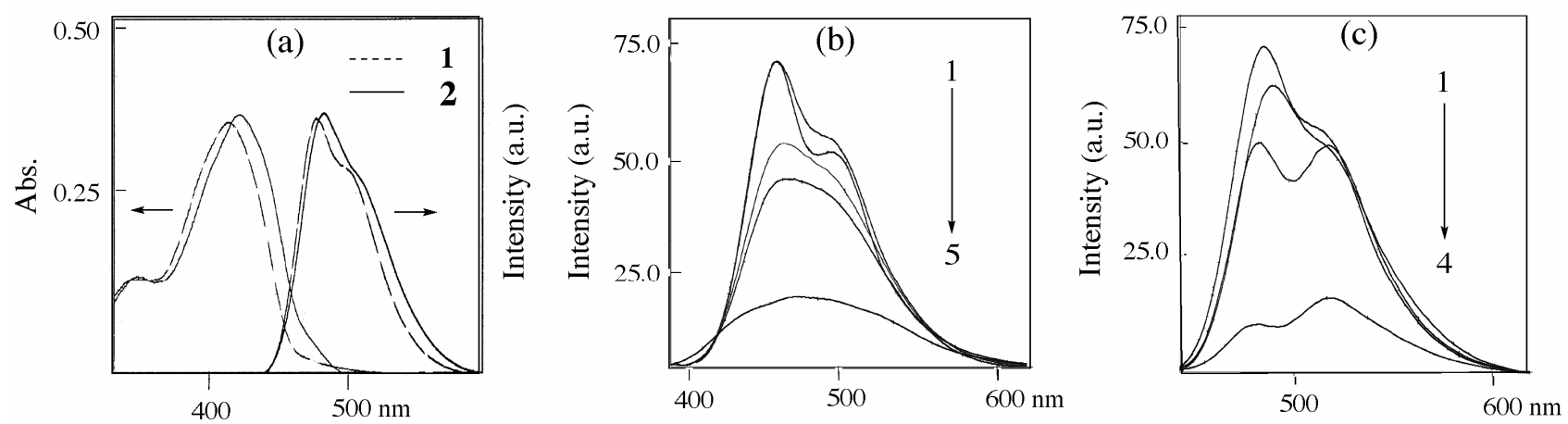

Fig. 2 

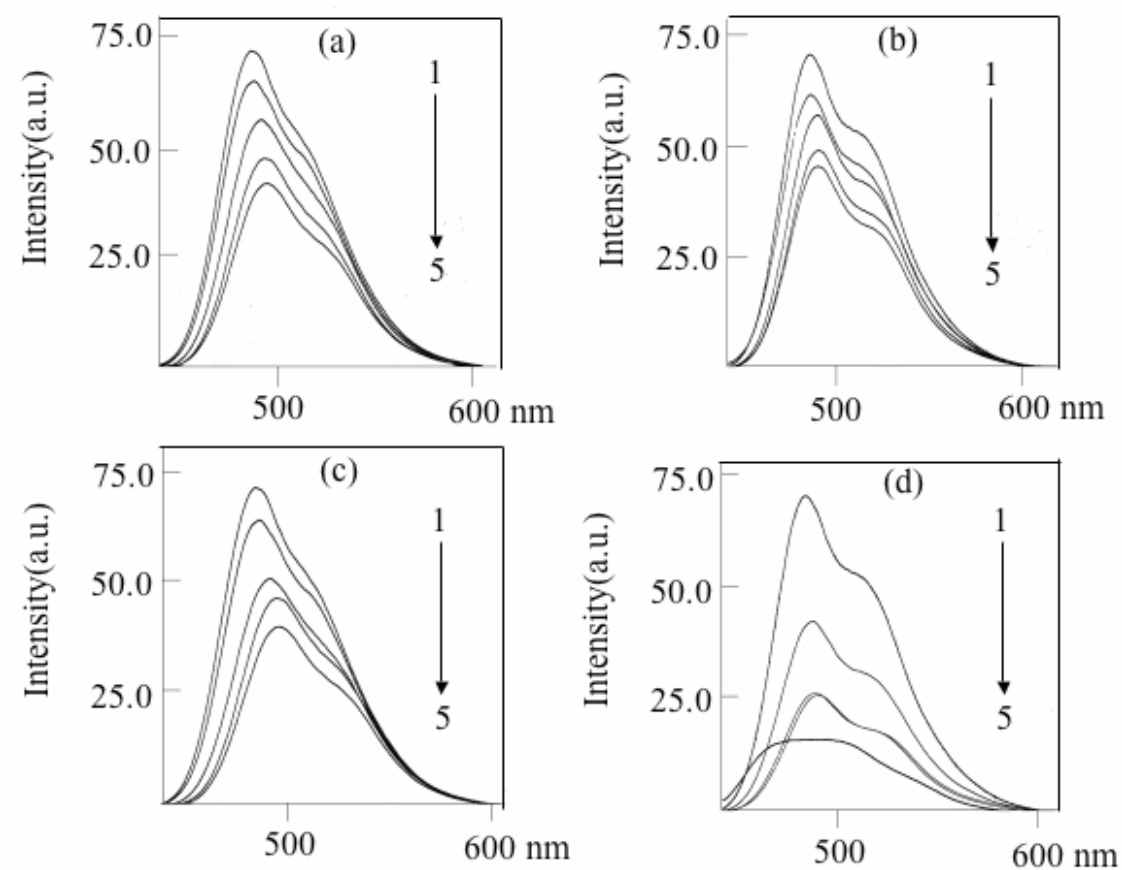

Fig. 3

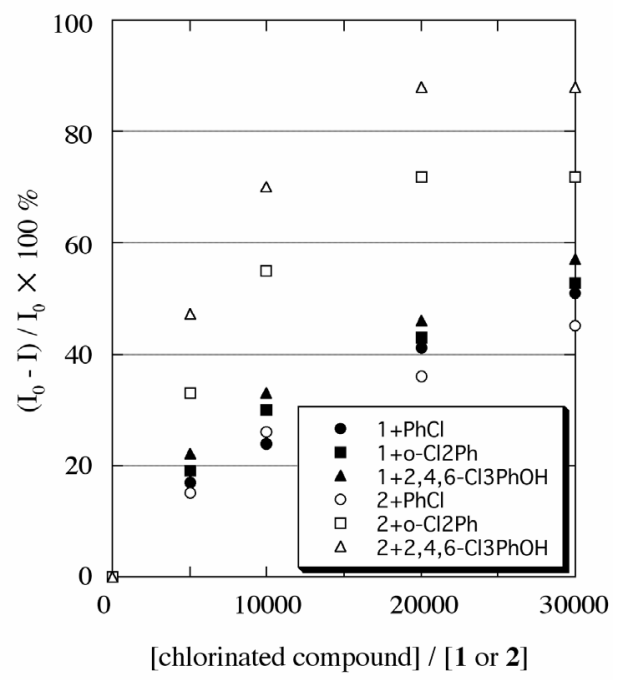

Fig. 4 

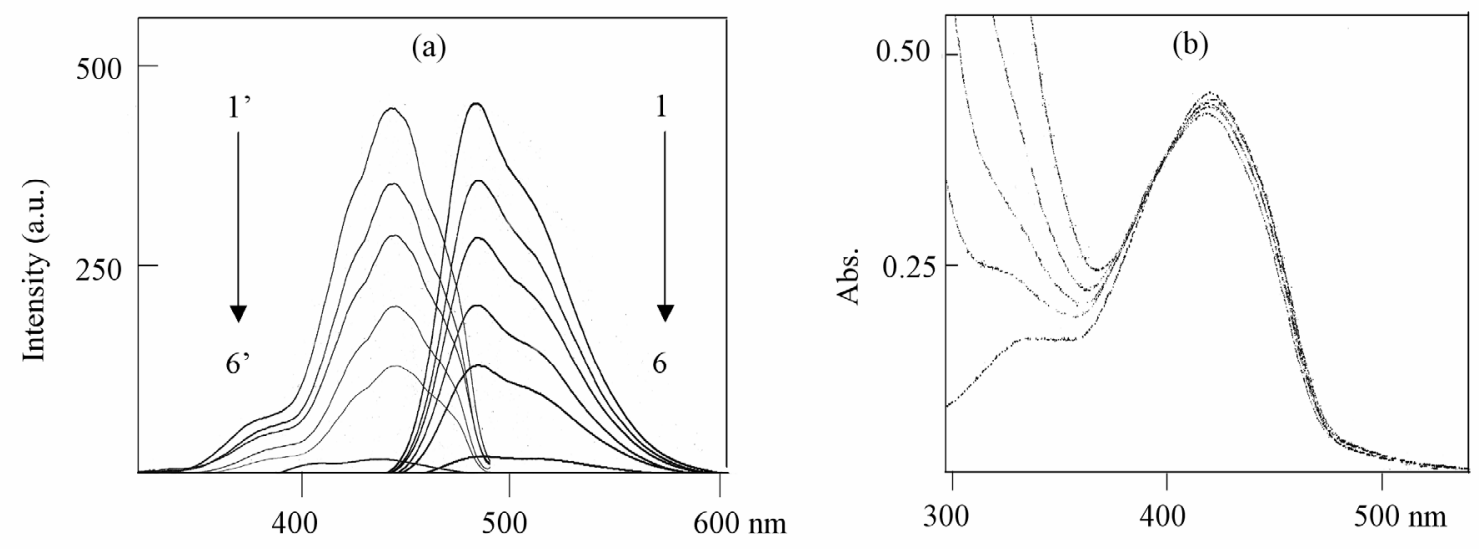

Fig. 5

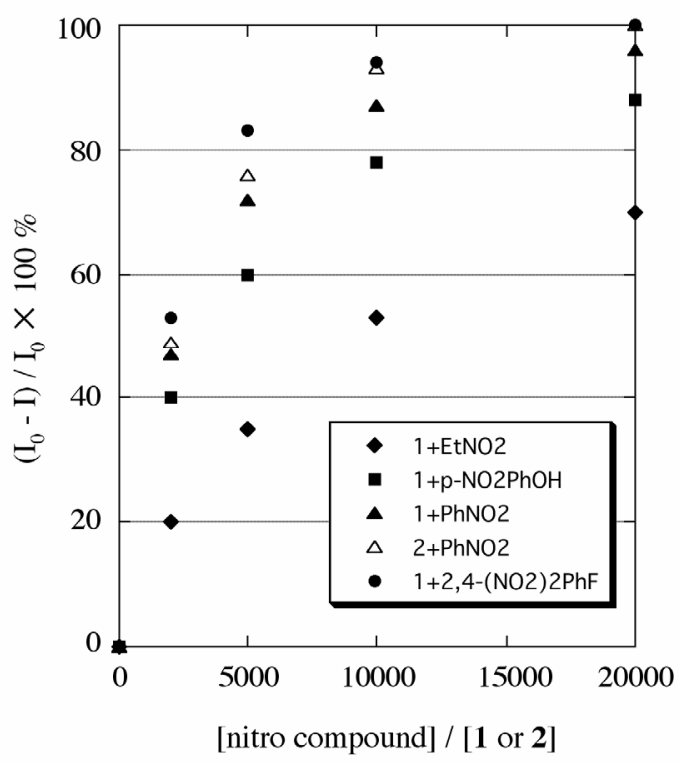

Fig. 6 

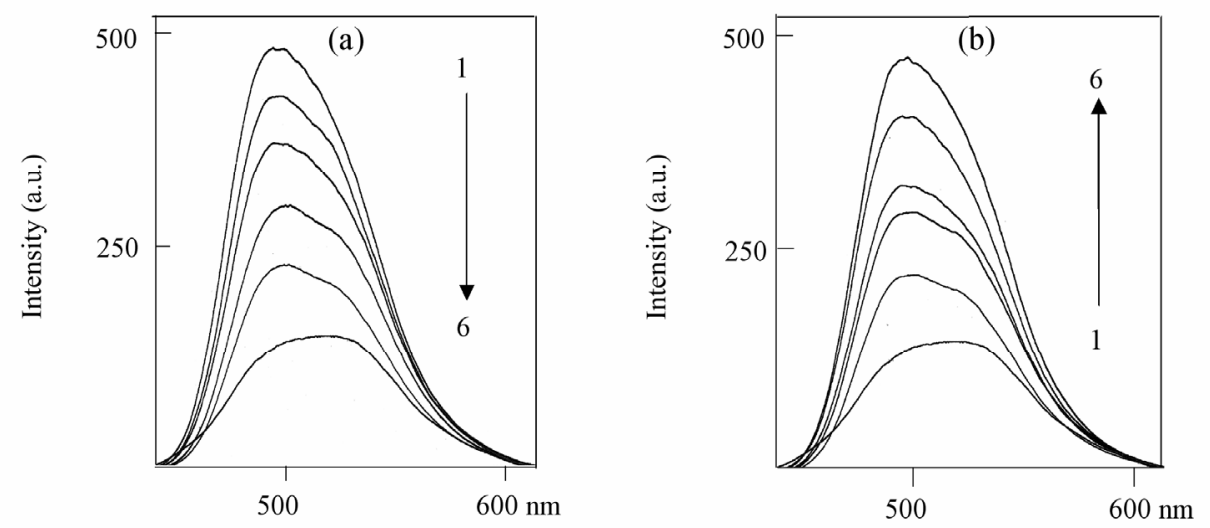

Fig. 7

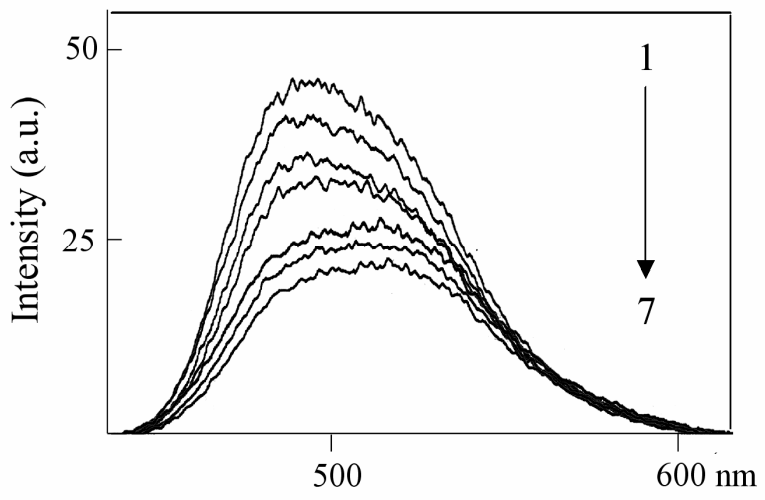

Fig. 8 


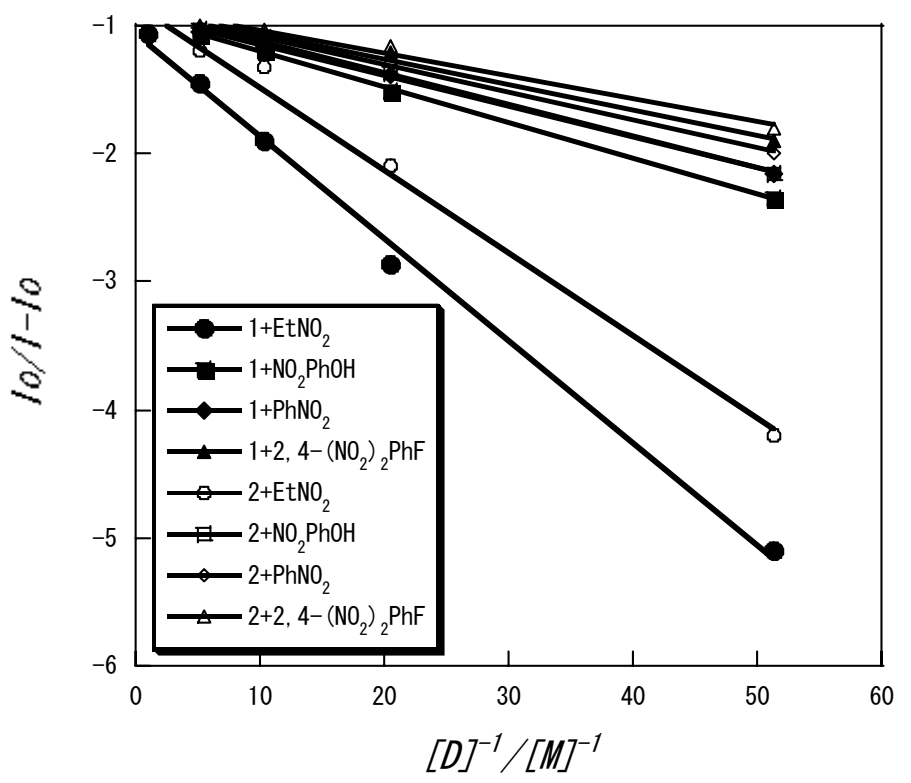

Fig. 9

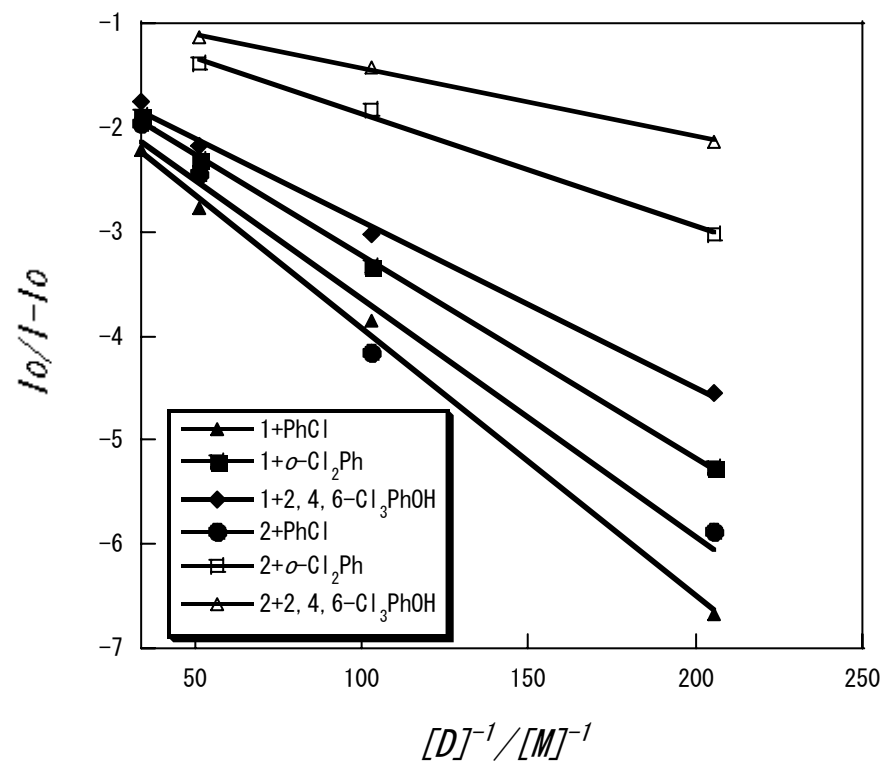

Fig. 10 


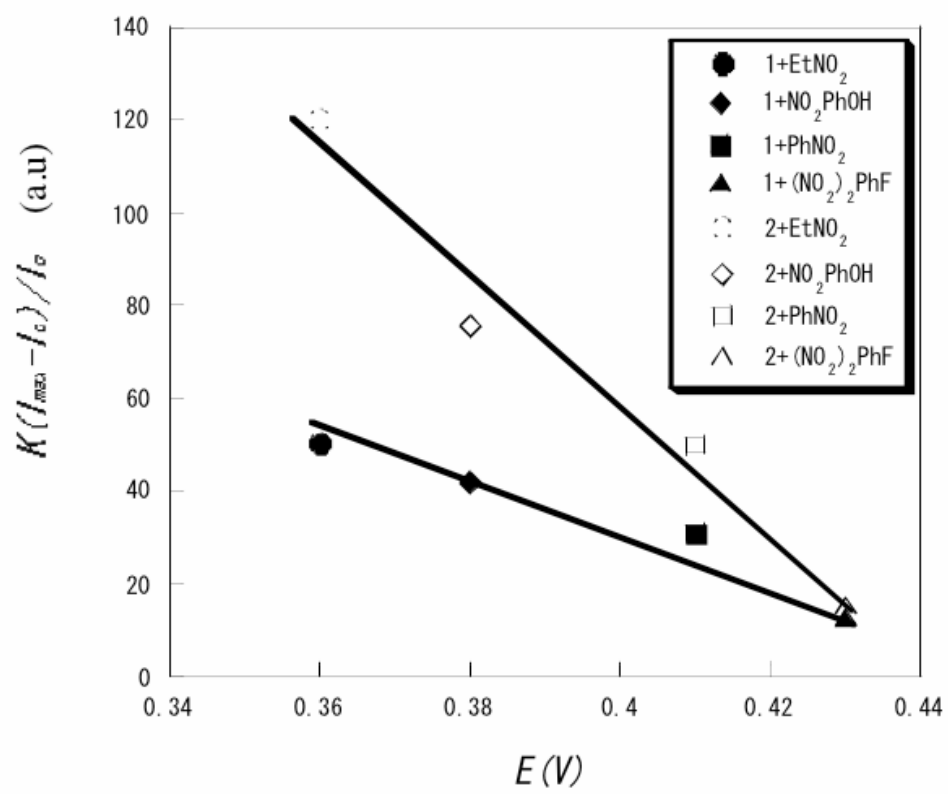

Fig. 11

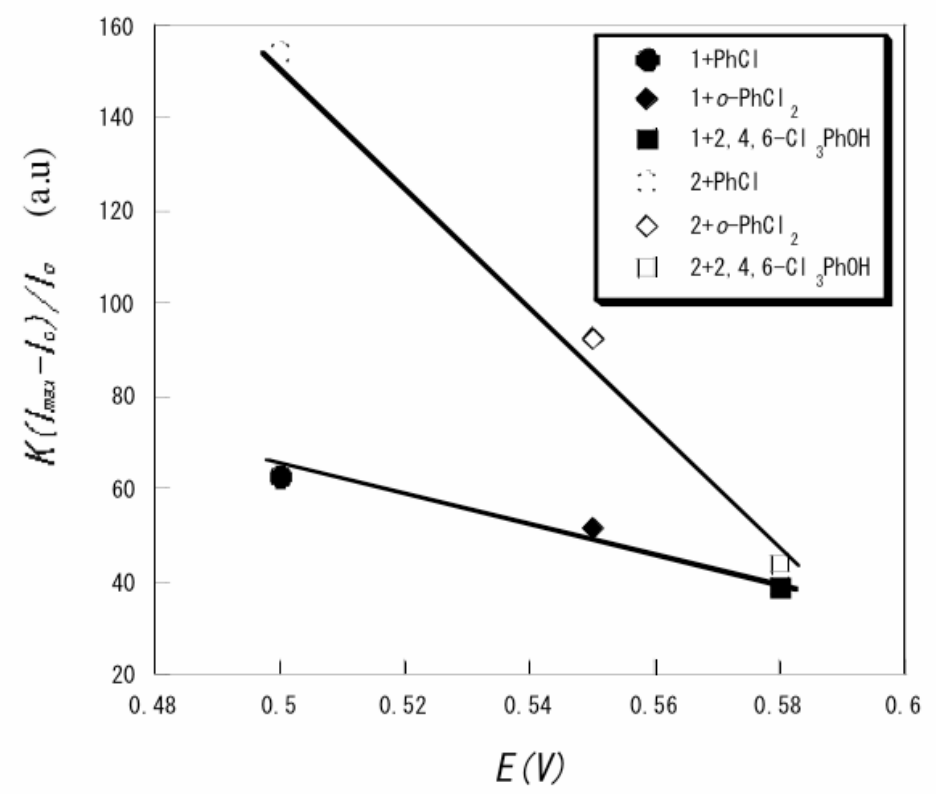

Fig. 12 